\title{
ECONOMICS
}

\section{EXPECTATIONAL STABILITY IN AGGREGATIVE GAMES}

\author{
by
}

Richard Cornes

Australian National University

Luciana C. Fioriniz

University of Western Australia

Wilfredo L. Maldonado

Catholic University of Brasilia 


\title{
Expectational Stability in Aggregative Games*
}

\author{
Richard Cornes $^{\dagger}$ \\ Luciana C. Fiorini \\ Wilfredo L. Maldonado $§$
}

April 1, 2017

\begin{abstract}
Using the replacement function associated with aggregative games, we analyze the expectational dynamics of the aggregate strategy of the game. We can interpret the Nash equilibrium of the game as the rational expectations equilibrium (REE) of the system, and we examine the expectational stability of the REE. We characterize local stability in terms of fundamentals and the REE itself. We illustrate the results through well-known aggregative games (Cournot games, Bertrand competition with differentiated goods, rent seeking games, and the public goods provision game) and analyze their global expectational dynamics.
\end{abstract}

${ }^{*}$ We would like to thank the participants of the $35^{t h}$ Australasian Economic Theory Workshop for their helpful comments. Wilfredo L. Maldonado would like to thank the CNPq of Brazil for financial support 305317/2003-2 and 471899/2003-8 and FAPDF for financial support 01/2016 and 193.001.325/2016.

$\dagger$ (deceased) Research School of Economics, Australian National University

${ }_{\ddagger}^{\ddagger}$ University of Western Australia. E-mail: luciana.fiorini@uwa.edu.au.

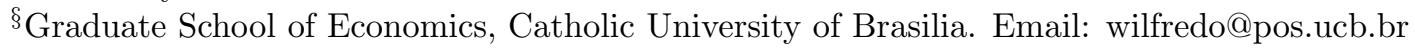




\section{Introduction}

In the aggregative games literature, studies extensively analyzed two main issues: (i) the existence and uniqueness of the Nash equilibrium (NE) and (ii) its stability for given dynamics. The dynamics may be defined in different ways, and the stability of the NE is interpreted as the robustness of the strategic profile. This work focuses on the second issue by defining the dynamics for a static aggregative game and analyzing the stability of the NE under such dynamics.

The most common dynamics defined in abstract aggregative games to analyze the stability of the NE are based on the best-reply function (Jensen (2016)). Jensen (2010) analyzes quasi-aggregative games with best-reply potentials and states the conditions for convergence to the NE. Possajennikov (2003) defines the aggregate-taking equilibrium of the game, where individual strategies do not affect the aggregate contribution, and proves its stability for games with a finite number of players. In a later work, Possajennikov (2015) considers players' beliefs about the marginal individual contribution to the aggregate strategy to define the dynamics of the game. He proves that only in games with an infinite number of players, consistent conjectures with respect to the NE are evolutionary stable. Similar to his previous work, a game with a finite number of players has an evolutionary stable aggregate-taking conjecture. Dindos and Mezzetti (2006) propose a random process for strategy adjustment in which an individual is randomly chosen from an infinite population to define the strategic transition of the game. They show that the dynamics is globally convergent when the actions are either strategic substitutes or strategic complements for all players.

For specific aggregative games and the stability of the NE, probably the most common game in the literature is the Cournot oligopolistic competition. Investigations into its stability started in the 1960s, when Hahn (1962) derived sufficient conditions for global stability in the equilibrium for dynamics defined by the temporary delays in the competitors' production. He proves that, independently of the number of players, the NE is always stable. However, Al-Nowaihi and Levine (1985) show that Hahn's conclusion is not valid for any number of firms when the adjustment follows a continuous-time best-reply dynamics. Since Al-Nowaihi and Levine (1985)'s result relies on the assumption that firms are strategic

substitutes, Okuguchi and Yamazaki (2008) removes this assumption to analyze the global 
stability of a unique interior Nash-equilibrium. They also analyze a rent-seeking game. Similar to Dastidar (2000), they consider an adjustment process that depends on the partial derivative of profits with respect to the firm's output. The direction of adjustment follows exactly the marginal response of profits to output scaled by a parameter representing the speed of adjustment. Chiarella and Szidarovszky (2002b) and Chiarella and Szidarovszky (2004) follow an alternative definition for the dynamics of individual strategies in which the transition is given by players' reaction functions. They prove the convergence to the NE and discuss the potential existence of limit cycles. Chiarella and Szidarovszky (2002a) provides an analogous analysis using the dynamics of the gradient of the individual objective functions in a rent-seeking game with non-linear costs, also proving the existence of limit cycles using the Hopf bifurcation theorem.

Following this research agenda, we propose new dynamics for aggregative games. It is simpler than the other dynamics already proposed in the literature because it has one dimension as the aggregate contribution is its unique state variable. We define the process from the principle of eductive learning and analyze stability based on the concept of expectational stability.

Guesnerie (1992) introduced the eductive dynamic (or eductive learning) as the foundation for rational expectations hypothesis-based rationalizability. It was also used in intertemporal macroeconomic models (Evans and Honkapohja (2003), Evans and Guesnerie (2005), Ellison and Pearlman (2011)), in general equilibrium models (Balasko (1994)) and in non-cooperative games (Evans and Guesnerie (1993), Gaballo (2013)). Essentially, eductive learning tests the stability of a rational expectations equilibrium in individuals' mental revision processes with respect to their own and other individuals' optimal decisions. If the rational expectation equilibrium is expectationally stable (ES), it is strongly rational. If the stability falls, the equilibrium is not robust to those revisions and is therefore excluded from rationalizable equilibria.

Specifically, in this work, we define an eductive learning process using beliefs about the aggregate contribution of the game as the state variable. Individuals formulate beliefs about the aggregate contribution and use their replacement function to implement a strategy that corresponds to the best composition of their expected aggregate state. Their actions reproduce the actual aggregate contribution of the game, which can be equal to the original belief (in this case the belief is the NE of the game) or closer to or farther from the NE than 
the initial belief. If the actual aggregate contribution is closer, then the NE is ES; when it is further away, then the NE is expectationally unstable (EU). There are two advantages to using the replacement function instead of the best response function. First, in practice, the value of the aggregate contribution is usually publicly available and thus taken as the reference variable (focal point) by players when they make decisions. Because players are aware that their individual contribution may affect the total contribution, they use their replacement functions rather than their best response function, where they would have to formulate beliefs about others' contributions. Second, stability under these dynamics would reinforce the NE as strongly rational (similar to earlier works), showing that small deviations of expectations of the aggregate would decrease or even vanish in actual decisions. If the NE is EU under this dynamics, small fluctuations in expectations would be amplified in the actual aggregate and we would observe unexpected results (as in many real world situations). The persistence of these fluctuations may indicate a change in paradigms. As prior studies discuss, one may wish to consider an aggregate-taking framework in some cases. It is worth noting that in all of the examples analyzed in our study, the NE of the aggregative game is ES for a limited number of players. Depending on the example and the payoff function used, this is not true when the number of players increases.

Because there are diverse results for this expectational stability, we focus on analyzing specific aggregative games here, all of which use standard functional forms given in the literature. We then discuss the global dynamics of the expectations in each example. We consider four games: the Cournot oligopolistic competition model in which both the priceelasticity of demand and the unit cost of firms are constant; the contest game, with either linear or non-linear technologies for lotteries; the public goods provision game with interior solutions; and the Bertrand oligopolistic competition model with differentiated prices. In all games, we find that for a bounded number of participants, the NE is ES. Small deviations in beliefs regarding the total contribution from the NE are attenuated by players' actual decisions following their replacement functions. For the Bertrand game and contest game with production functions of lotteries that are sufficiently concave, stability exists, even when the number of participants is large. As we discussed above, in the case of an unstable NE, small deviations in expectations are amplified in the actual aggregates and this may explain large deviations in prices, quantities, contributions, and so on.

This article is divided into four sections. In Section 2, we define the replacement func- 
tion in an aggregative game with eductive learning defined by the aggregate replacement function. We also present the general theorem for the local expectational stability (instability) of the NE in a general homogeneous aggregative game. In Section 3, we analyze the expectational stability of the NE in four aggregative games: Cournot oligopoly competition, contest games, public goods contribution games, and Bertrand oligopoly competition with differentiated products. In Section 4, we provide some conclusions. The proofs of propositions are given in the Appendix.

\section{Expectational Dynamics in Aggregative Games}

In this section, we define the expectational dynamics for the aggregate strategy of a general aggregative game and its associated concept of stability. Consider an aggregative game played by a finite number of individuals $N \geq 2$. Formally, the game is represented by $\Gamma=\left(S_{i}, u_{i}\right)_{i=1}^{N}$, where for each player $i \in\{1,2, \cdots, N\}, S_{i} \subset \mathbb{R}$ is the set of strategies and $u_{i}: S_{i} \times S \rightarrow \mathbb{R}$ is the payoff function depending on the individual strategy $x_{i} \in S_{i}$ and the aggregate strategy $X=\sum_{j=1}^{N} x_{j} \in S$.

In aggregative games, Okuguchi (1993), Cornes and Hartley (2007a), and Cornes and Hartley (2007b) use the best response function defined by aggregate decisions to analyze equilibrium properties. The next two definitions follow their approach.

Definition 1. The compensation function for player $i \in\{1, \cdots, N\}, \phi_{i}: S \times S_{i} \rightarrow S_{i}$ is

$$
\phi_{i}(X, y)=\arg \max _{z \in S_{i}} u_{i}(z, X-y+z)
$$

Strictly speaking, the compensation function provides the optimal contribution to the aggregate decision $X$ that compensates for a loss of $y$ units. This compensation may be higher or lower than the lost amount $y$. When both are equal, the following definition applies.

Definition 2. The replacement function of player $i \in\{1, \cdots, N\}$ is the function $r_{i}: S \rightarrow$ $S_{i}$ associated with each aggregate decision $X \in S$ as the fixed point of the function $\phi_{i}(X, \cdot)$, namely:

$$
r_{i}(X)=\left\{x \in S_{i} ; \phi_{i}(X, x)=x\right\}
$$


In general, equation (1) may define a set-valued function; however, we will assume that the set on the right-hand side of equation (1) is a singleton. Thus, $r_{i}(X)$ is individual $i$ 's optimal contribution in the composition of the aggregate contribution $X$. Note the difference with the best-reply function, which depends on others' contributions. In $r_{i}(X)$, we have the actual optimal contribution of player $i$ in the composition of a perceived $X$.

The sum $\sum_{j=1}^{N} r_{j}(X)$ is not necessarily equal to $X$ and the NE occurs when the equality $\sum_{j=1}^{N} r_{j}(X)=X$ holds. Specifically, a NE is a profile of contributions $\left(x_{i}^{*}\right)_{i=1}^{N} \in \Pi_{i=1}^{N} S_{i}$ such that $\sum_{j=1}^{N} r_{j}\left(X^{*}\right)=\sum_{j=1}^{N} x_{j}^{*}=X^{*}$. Note that given the aggregate strategy $X^{*}$, the NE strategies are completely defined by the replacement functions as $x_{j}^{*}=r_{j}\left(X^{*}\right)$. Thus, we also denote $X^{*}$ as the NE of the game.

We can obtain an insightful interpretation of the replacement function (1) if we include the concepts of expectational dynamics into the model. In general, to play a NE of a non-cooperative game, each player's expectations about others' strategies must coincide with the strategy profile of the NE. Rather, in aggregative games, players only need to form expectations about the aggregate strategy of the game because replacement functions define their individual optimal strategies. In practice, such expectations' formation, which can be interpreted as a focal point of the game, may be derived from market surveys publicly available, policy market targets or aggregate indices of expectations.

Thus, if $X^{(E)} \in S$ is the expected aggregate contribution, then the actual contribution of player $i$ is $x_{i}^{(A)}=r_{i}\left(X^{(E)}\right)$. As a consequence, the actual contribution of the game is $X^{(A)}=\sum_{j=1}^{N} r_{j}\left(X^{(E)}\right)$; therefore, we have the following definition:

Definition 3. The perceived-to-actual (P-T-A) map $\rho: S \rightarrow S$ associated with the aggregative game $\Gamma$ is defined by:

$$
\rho(X)=\sum_{j=1}^{N} r_{j}(X)
$$

The P-T-A map (also called the aggregate replacement function in Cornes and Hartley (2007a)) transforms the perceived value of the aggregate contribution to its actual value. The map allows us to define the dynamics of the eductive process:

$$
X_{(\tau+1)}=\rho\left(X_{\tau}\right) ; \tau=0,1, \ldots
$$


It is easy to see that $X^{*}$ is a fixed point of $\rho$ if and only if $X^{*}$ is a $\mathrm{NE}$ of $\Gamma$. The stability of $X^{*}$ under the dynamics defined in (2) determines whether the NE is robust to small deviations of the expectations about it. The formal definition of expectational stability is:

Definition 4. An NE $X^{*}$ of the aggregative game $\Gamma$ is (locally) ES if the dynamics (2) is (locally) stable in $X^{*}$. Analogously, $X^{*}$ is (locally) EU if the dynamics (2) is (locally) unstable in $X^{*}$.

Guesnerie (1992) used the expectational stability of eductive learning as the foundation for rationalizability based on the rational expectations hypothesis. Evans (1985) previously used the notion of ES in dynamic models and Evans and Guesnerie (1993) later applied the concept of ES to static models. In general equilibrium models, Balasko (1994) used expectational stability in a two-period setting to show the broad use of ES. In most of those works, ES serves either as a criterion for selecting from a multiplicity of equilibria or to test the robustness of the equilibrium. In aggregative games, we apply the concept of ES to test the robustness of the NE with respect to small deviations of beliefs about the aggregate contribution. These beliefs will function as a focal point for the game. Thus, if the NE is ES, the actual contributions will reduce the small deviations in beliefs about the aggregate contribution from the equilibrium, and eventually the NE will be reached. On the contrary, if the NE is EU, individuals' actual aggregate decisions will amplify a small deviation from equilibrium.

The local expectational stability of the NE in aggregative games depends on the absolute value of the derivative of the P-T-A map $\rho$ evaluated at the equilibrium. We consider the case in which players have the same payoff function since analyzing an aggregative game with heterogeneous players may lead to diverse conclusions. Analyzing the homogeneous case sheds light on the determinants of stability in each specific game. In particular, we show that the local expectational stability of the NE depends on the second derivatives of the payoff functions evaluated at equilibrium and on the number of players. Later, we present some examples that illustrate our results and provide the global dynamics of the expectations.

Consider $\Gamma^{H}$ as the (homogeneous) aggregative game defined by $N \geq 2$ identical players with payoff functions $u: \mathbb{R}_{+}^{2} \rightarrow \mathbb{R}$. Given the aggregate strategy of all players, $X \in \mathbb{R}_{+}$, 
$u(x, X)$ is the payoff of a player who chooses the strategy $x \in \mathbb{R}_{+}$. Furthermore, in this homogeneous setting, $u_{i j}$ denotes the second-order derivative of the utility function with respect its arguments $i$ and $j$. Our main general result relies on the following assumptions:

Assumption 1. The function $u$ is a continuous function in its domain, a $C^{2}$ function in the interior of its domain, and:

(i) There exists an $N E X^{*}>0$;

(ii) $u_{11}\left(x^{*}, X^{*}\right)+u_{12}\left(x^{*}, X^{*}\right) \neq 0$, where $x^{*}=X^{*} / N$.

The first part of the assumption states that in equilibrium the aggregate contribution is positive. The second part is a regularity condition of the equilibrium.

To prove existence of equilibrium in the Cournot model, Frank-Jr. and Quandt (1963) and McManus (1964)'s works preceded Selten (1970)'s seminal work on aggregative games. Researchers proposed different techniques for proofs of the Cournot model in the two subsequent decades (Szidarovsky and Yakowitz (1977), Roberts and Sonnenschein (1976), Novshek (1985)). Dubey et al. (2006) applied the same technique as Novshek (1985) without assuming that firms' strategy sets are convex and generalized his proof for a larger class of aggregative games. Jensen (2010) introduced the concept of quasi-aggregative games and derived sufficient conditions for the existence of a pure-strategy NE. Corchón (1994) showed the existence of a unique equilibrium in aggregative games. In the following decade, Cornes and Hartley (2005b) used a geometrical approach to derive sufficient conditions for the existence of equilibrium in aggregative games.

Before presenting our general result, we define parameter $\Delta$. For $i, j \in\{1,2\}$, let $u_{i j}^{*}=u_{i j}\left(\frac{X^{*}}{N}, X^{*}\right)$ and consider $\Delta$ as:

$$
\Delta=\frac{u_{12}^{*}+u_{22}^{*}}{u_{21}^{*}+u_{11}^{*}}
$$

Based on Assumption 1, we can state sufficient conditions of $\Delta$ to obtain the expectational stability and expectational instability.

Theorem 1. Suppose that Assumption 1 holds for the homogeneous aggregative game $\Gamma^{H}$. The $N E X^{*}$ is locally ES if $|\Delta|<N^{-1}$. Reciprocally, if $|\Delta|>N^{-1}$, the $N E X^{*}$ is locally $E U$. 
Notice that the NE $X^{*}$ in an aggregative game depends on the number of participants $N$, as does the parameter $\Delta$. In the examples we analyze in the next section, we will show that a sufficient condition for obtaining expectational stability is that the number of participants is not too large. The interpretation of ES is that the signal the players receive about the aggregate contribution (the expected aggregate contribution) is robust to small perturbations. In this case, the expectations of the aggregate contribution work as a good coordination device to reach the NE. On the contrary, if the NE is locally EU, a small perturbation in the signal triggers a dispersion from the NE and we may observe under- or over-provision of total contributions to the aggregate strategy, as discussed in the Introduction.

It is worth noting that NE stability in the dynamics of expectations precludes the existence of a continuum of equilibria around it. This is because with multiple equilibria, the P-T-A map $\rho(X)$ coincides with a segment of the diagonal of the first quadrant (namely, $\rho(X)=X$ for all $X$ in a neighborhood of $\left.X^{*}\right)$, implying that $\rho^{\prime}\left(X^{*}\right)=1$, which does not correspond to the stability condition.

\section{Examples of Expectational Dynamics in Aggrega- tive Games}

In Theorem 1, we stated conditions for the local stability of the aggregative game NE in the dynamics of expectations. In this section, we provide some explicit examples of aggregative games and analyze stability globally. We consider payoff functions with standard specific parameterized functional forms; thus, the global dynamics will depend on the parameters of the models.

\subsection{Cournot games}

Dynamic oligopolies are extensively studied in the literature (Okuguchi (1976) and Okuguchi and Szidarovszky (1999)). Chiarella and Szidarovszky (2002b) detected the presence of cycles in oligopolies when firms experience lags in executing their strategies. In this sub- 
section, we analyze the stability of eductive learning depending on the number of firms and the price elasticity of demand.

Consider $N \geq 2$ firms competing à la Cournot in a market with an isoelastic demand function $p=A X^{-a}$, where $p$ is the unit price of the good, $X$ is the total market demand, $A>0$ is a parameter, and $a>0$ is the inverse of the market demand elasticity $\frac{p}{X} \frac{d X}{d p}=-\frac{1}{a}$. Firm $i$ has constant marginal costs of production $c_{i}$ and zero fixed costs. In order to guarantee that the second-order condition in the profit maximization problem of firms is satisfied, we assume that $a \geq 1$.

The payoff function of firm $i$ is $u_{i}(x, X)=A X^{-a} x-c_{i} x$. To find the replacement function, we must solve the first-order condition $u_{i 1}(r, X)+u_{i 2}(r, X)=0$, which is equivalent to $A X^{-a}-c_{i}-a A X^{-a-1} r=0$; therefore, $r_{i}(X)=a^{-1} X\left[1-c_{i} A^{-1} X^{a}\right]$ if it is non-negative and zero otherwise. Considering the case in which firms are homogeneous and therefore $c_{i}=c$ for all $i$, the P-T-A map is:

$$
\rho(X)=\frac{N}{a} X\left(1-\frac{c}{A} X^{a}\right)
$$

Equation (4) defines a unimodal map of the interval $\left[0,\left(c^{-1} A\right)^{1 / a}\right]$ that allows us to state the following result for the expectation dynamics.

Proposition 1. In a Cournot model with $N \geq 2$ firms with the same constant unit cost $c>0$ and competing in a market with inverse demand $p=A X^{-a}$ :

(i) There exists a unique strictly positive $N E X^{*}=\left(\frac{A}{c}\left(1-\frac{a}{N}\right)\right)^{1 / a}$ if and only if $a<N$;

(ii) The NE $X^{*}$ is monotonically ES (i.e., the sequence defined by (2) is strictly increasing or decreasing from a given $\tau$ and converges to $X^{*}$ ) if and only if $N \leq a+1$;

(iii) The NE $X^{*}$ is oscillating ES (i.e., the sequence defined by (2) oscillates around and converges to $X^{*}$ ) if and only if $a+1<N \leq a+2$;

(iv) The NE $X^{*}$ is not ES and the dynamics (2) is chaotic on the interval $I=\left[0,\left(c^{-1} A\right)^{1 / a}\right]$ if and only if $a+2<N \leq v(a)^{1}$;

\footnotetext{
${ }^{1}$ We define the function $v(x)=(1+x)^{1+x^{-1}}$ for all $x>0$. It is interesting and not difficult to prove that $v(x)$ is a strictly increasing function and $v(x)>e+x$ for all $x>0$, where $e$ is the Euler number.
} 
(v) The NE $X^{*}$ is not ES and the dynamics (2) is chaotic in a Cantor subset of the interval $I=\left[0,\left(c^{-1} A\right)^{1 / a}\right]$ if and only if $v(a)<N$;

At this point, it is important to highlight some results from Proposition 1. Part (i) imposes a lower bound $\left(N^{-1}\right)$ on the market demand elasticity to allow for an oligopoly. Alternatively, this implies a lower bound on the number of firms. On the other hand, we require an upper bound on the number of firms to obtain ES. This is stated in parts (ii) and (iii). Figures 1 to 4 illustrate parts (ii) to (iv) of Proposition 1, assuming that $A=c$, thus the dynamics takes place on the interval $[0,1]$.

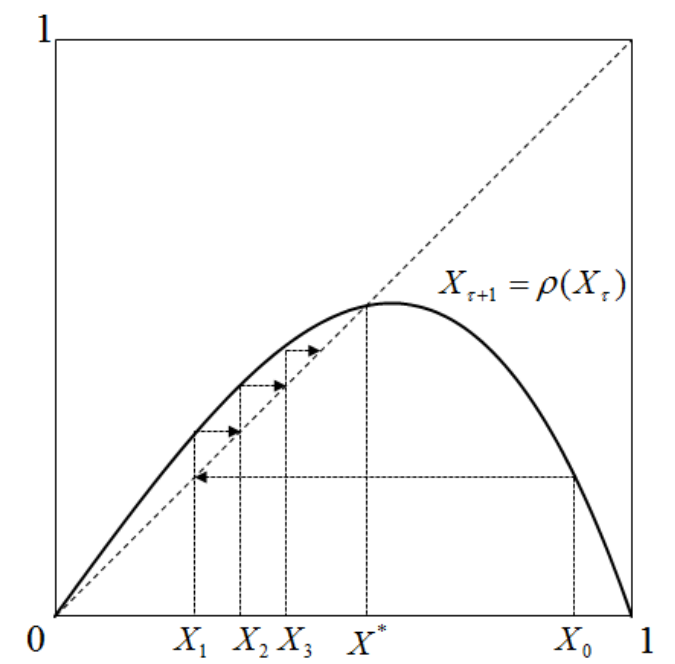

Figure 1: Expectations dynamics in the Cournot model when $a<N \leq a+1$

In Figure 1, a small deviation from the rational expectations equilibrium will trigger a sequence of aggregate production that converges to the NE monotonically. This will reflect a counterpart in prices, which will steadily converge to the equilibrium prices of the system. Figure 2 also shows convergence, but now following an oscillating path.

Part (iv) is quite interesting as it establishes an upper bound $(a+2)$ for the number of firms as a necessary condition for ES. This upper bound is inversely related to the elasticity of demand, meaning that more inelastic markets require a smaller number of firms for an ES equilibrium. If the number of firms exceeds this threshold, any deviation in expectations from the NE will take the actual total production far from the equilibrium. In this case, 


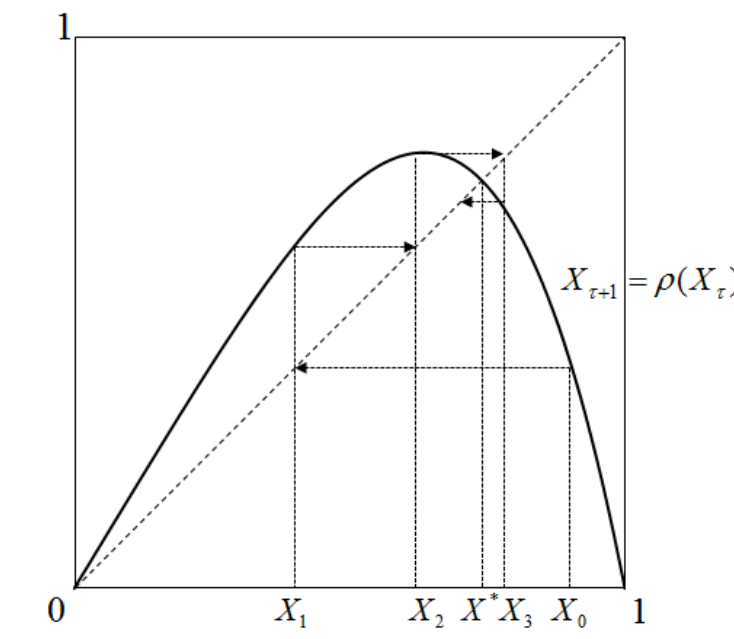

Figure 2: Expectations dynamics in the Cournot model when $a+1<N \leq a+2$

we can expect deviations from the actual total supply, and consequently from the unit price of the good. This sort of non-convergence to the NE was found by Al-Nowaihi and Levine (1985) and Chiarella and Szidarovszky (2004). The former showed the presence of instability when $N>5$. In our example, the sequence of expectations revisions remains and exists in almost all points on the interval $I$, as shown in Figure 3.

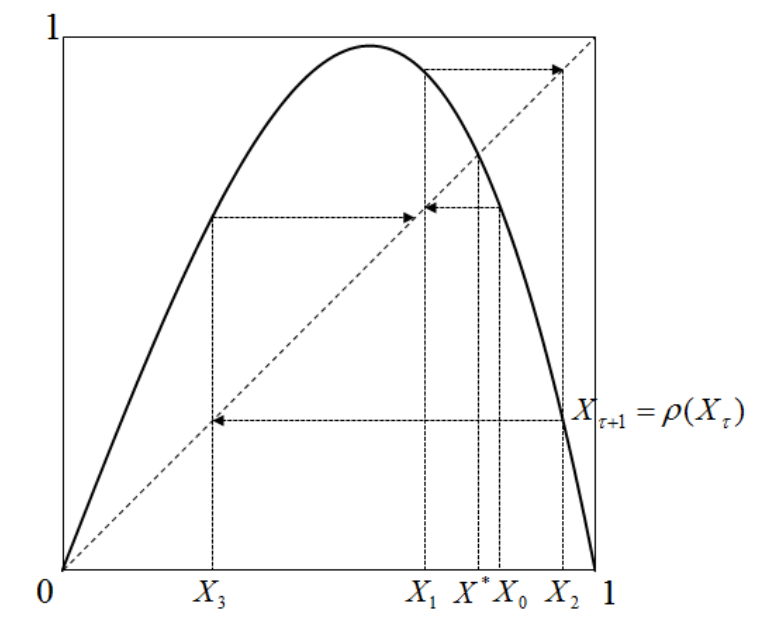

Figure 3: Expectations dynamics in the Cournot model when $a+2<N \leq v(a)$

In this example, there is a close connection between expectational stability and concentration of firms in the market. Due to the homogeneity of firms, the Herfindahl-Hirschman 
index (HHI), which measures the level of concentration in an industry, is equal to $1 / N$. Thus, a low number of firms, and hence a high degree of concentration, may be due to the stability of the equilibrium in expectations of total production (or the expected equilibrium price). On the contrary, with a low HHI, there is a loss of coordination in expectations regarding total production due to the equilibrium instability of the dynamics of expectations. We can run a reverse exercise. As a rule of thumb, an HHI below 0.15 indicates an industry with a low concentration index. In our example, this corresponds to $N \geq\left\lfloor 0.15^{-1}\right\rfloor+1=7$ firms. In our analysis, expectational instability occurs when $7>|\epsilon|^{-1}+2$, so the minimum price elasticity (in modulus) for a competitive industry is $(7-2)^{-1}=0.2$. Therefore, this part of the proposition relates to the number of firms, elasticity, and industry concentration.

Finally, the most intriguing case is part $(v)$, which states that if the number of firms is large enough (greater than $v(a)$ ), then the NE is not ES. In addition, the dynamics of expectations occurs in a topologically invisible set (a Cantor set) given by $C=\bigcap_{i=1}^{\infty} \rho^{-i}(I)$ as illustrated in Figure 4.

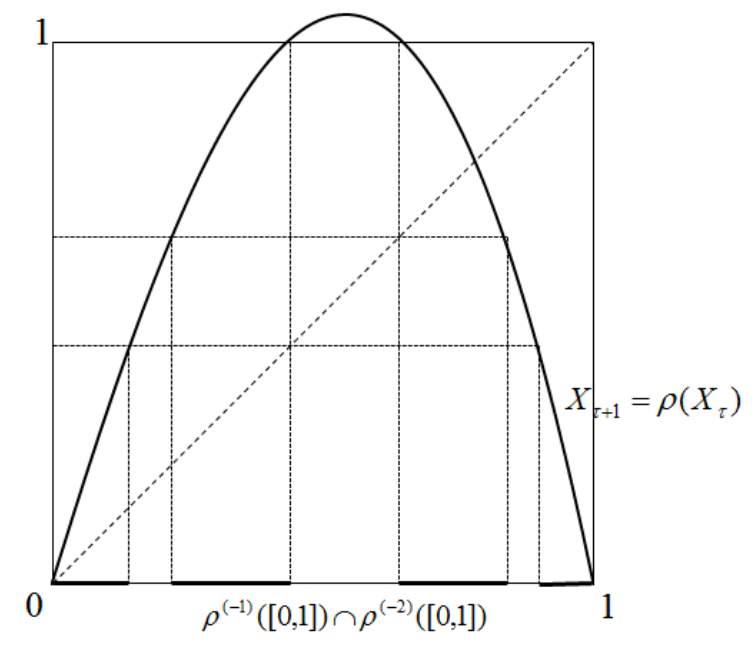

Figure 4: Expectations dynamics in the Cournot model when $v(a)<N$

Summing up, in a model with the stated functional specifications, the expectational stability of the NE is conditional on an upper bound on the number of firms. This means that the industry will remain in an oligopolistic equilibrium if firms take the aggregate production (or the market price for the good) as the focal point in their individual decisions 
and the number of firms is below a parameter that depends on the price elasticity of the market demand. The following picture shows the expectational dynamics behavior for each value of the price elasticity of demand.

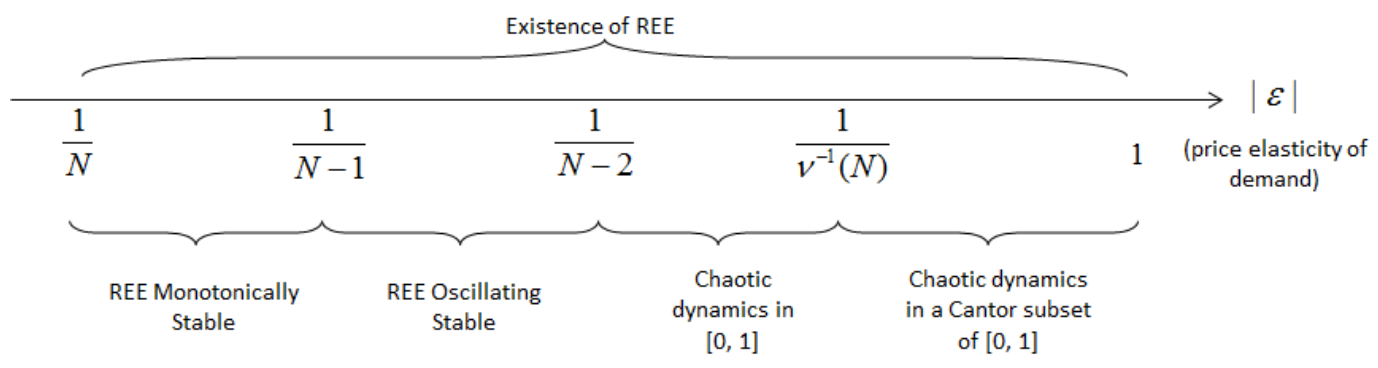

\subsection{Contest games}

In this model, there are $N \geq 2$ contestants in a "winner takes all" contest with prize $R$. The probability of receiving the prize depends on the individual and aggregate efforts that each contestant applies. Namely, if contestant $i$ applies an effort $z_{i}$, measured in monetary units, then the probability of winning the prize is:

$$
p_{i}=\frac{f_{i}\left(z_{i}\right)}{\sum_{j=1}^{N} f_{j}\left(z_{j}\right)}
$$

where the function $f_{i}$ is a strictly increasing and concave function called the production function for lotteries for player $i$ (see Szidarovsky and Okugushi (1997)). The problem of the risk neutral contestant $i$ is

$$
\max _{z_{i} \geq 0} p_{i} R-z_{i}=\max _{z_{i} \geq 0} \frac{f_{i}\left(z_{i}\right)}{\sum_{j=1}^{N} f_{j}\left(z_{j}\right)} R-z_{i}
$$

As in Cornes and Hartley (2005a), $f_{i}\left(z_{i}\right)$ can be replaced by $x_{i}$. Thus, problem (5) becomes

$$
\max _{x_{i} \in f_{i}^{-1}\left(\mathbb{R}_{+}\right)} \frac{x_{i}}{X} R-f_{i}^{-1}\left(x_{i}\right)
$$


where $X=\sum_{j=1}^{N} x_{j}=\sum_{j=1}^{N} f_{j}\left(z_{j}\right)$. We consider two cases: linear and non-linear production functions for lotteries $f_{i}\left(z_{i}\right)$.

\subsubsection{The linear technology case}

Let us suppose that $f_{i}(z)=a_{i} z$ for all $i$, as exemplified in Tullock (1980). In that case, the payoff for individual $i$ is $u_{i}(x, X)=\frac{x}{X} R-a_{i}^{-1} x$. As discussed in Okuguchi and Yamazaki (2008), this case is similar to the Cournot oligopoly model with unit price elasticity in Subsection 3.1. The replacement function is given by $r_{i}(X)=X\left(1-\left(a_{i} R\right)^{-1} X\right)$ and for the homogeneous case $\left(a_{i}=a\right.$ for all $\left.i\right)$, the P-T-A map is $\rho(X)=N X\left(1-(a R)^{-1} X\right)$ if $X \leq a R$.

Proposition 2. In the contest game model with $N \geq 2$ participants, prize $R$, and linear technologies for the production function of lotteries $f(z)=a z$ :

(i) There exists a unique strictly positive $N E X^{*}=\left(1-N^{-1}\right) a R$;

(ii) $X^{*}$ is monotonically ES if and only if $N=2$;

(iii) $X^{*}$ is oscillating ES if and only if $N=3$;

(iv) $X^{*}$ is EU and the dynamics (2) is chaotic in $[0, a R]$ if and only if $N=4$;

(v) $X^{*}$ is EU and the dynamics (2) is chaotic in a Cantor subset of $[0, a R]$ if and only if $N \geq 5$.

As in the Cournot oligopoly, the greater the number of players, the lower the stability of the equilibrium for the expectational dynamics. We reinterpret the conclusions of Subsection 3.1 and say that, as the number of players increase, the contestants see the probability of winning $(x / X)$ as proportional to their own effort $(x)$, assuming that the counterpart $1 / X$ is constant (parallel with the case of price-taking firms). This is true when the unit cost of effort (or production for the oligopoly model) is constant. In the next case, we will introduce increasing unit costs to analyze its effect on the stability of the equilibrium. 


\subsubsection{The non-linear technology case}

We now consider the technology for lotteries given by $f_{i}(z)=a_{i} z^{\alpha_{i}}$, where $\alpha_{i} \in(0,1)$ represents the elasticity of the production function of lotteries with respect to effort. Small values of $\alpha_{i}$ imply that increases from the zero effort are highly productive in terms of the probability of winning. Reciprocally, large values of $\alpha_{i}$ (keeping it below one) imply that increases from zero effort are not highly productive in terms of winning.

In this case, the payoff function of individual $i$ is $u_{i}(x, X)=\frac{x}{X} R-b_{i} x^{\sigma_{i}}$, where $\sigma_{i}=$ $\frac{1}{\alpha_{i}}>1$ and $b_{i}=a_{i}^{-\sigma}$. This resembles the case of the Cournot oligopolistic competition model with unit price elasticity of demand and increasing unit costs. To see this, note that in the model in Subsection 3.1, the cost function $c(x)=x^{\sigma}$ corresponds to a production function for the physical good $f(z)=z^{1 / \sigma}=z^{\alpha}$.

As in our previous examples, we restrict the analysis to the homogeneous case by setting $a_{i}=a$ and $\alpha_{i}=\alpha$ for all $i$, and for simplicity, we fix $a=1$. The following lemma states the existence of players' replacement functions and describes its properties and those of its associated P-T-A map.

Lemma 1. For a contest model with prize $R>0$ and technologies for lotteries $f(z)=z^{\alpha}$ :

(i) The replacement function $r(X)$ exists and is a continuous and differentiable function for all $X>0$;

(ii) The replacement function is a unimodal map with the following properties: $r(X)<X$ for all $X>0, \lim _{X \rightarrow 0} r(X)=\lim _{X \rightarrow+\infty} r(X)=0 ; \lim _{X \rightarrow 0} r^{\prime}(X)=1$, and the maximum $r$ is attained at $X^{m}=2\left(\frac{\alpha R}{4}\right)^{\alpha}$;

(iii) The corresponding P-T-A map $\rho$ is a unimodal map with the following properties: $\rho(X)<N X ; \lim _{X \rightarrow 0} \rho(X)=\lim _{X \rightarrow+\infty} \rho(X)=0 ; \lim _{X \rightarrow 0} \rho^{\prime}(X)=N$.

Figure 5 shows the replacement function for the contest game with the specified parameter values.

The P-T-A map inherits the same properties as the replacement function, amplified by the number of participants. 


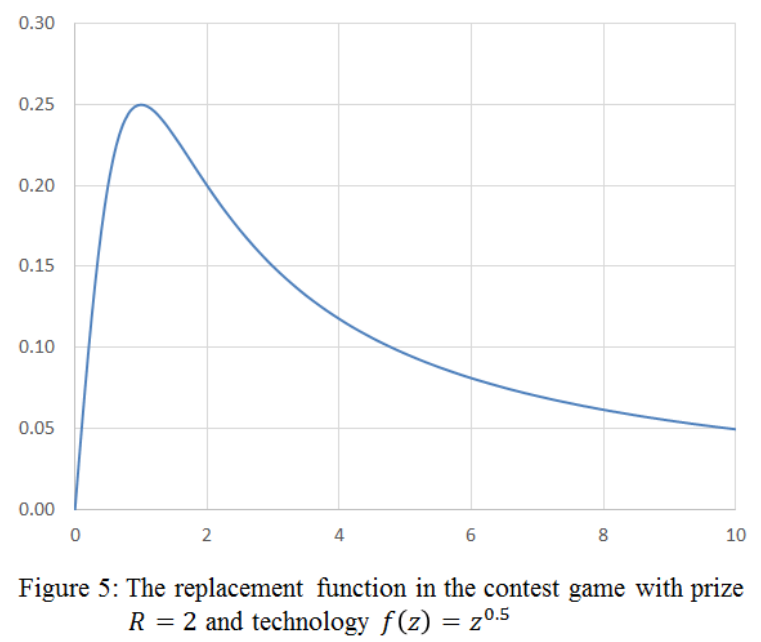

In all of our previous examples, the stability of the NE in the expectations dynamics is lost when the number of participants increases. However, in this example, the dynamics may be ES independently of the number of players, as stated in the next proposition.

Proposition 3. In a contest game with non-linear technology for lotteries given by $f(z)=$ $z^{\alpha}, \alpha \in(0,1)$, and $N \geq 2$ contestants, we have the following:

(i) The unique strictly positive $N E$ is $X^{*}=\left(\operatorname{R\alpha } N^{\alpha^{-1}-2}(N-1)\right)^{\alpha}$;

(ii) If $\alpha \in(0,1 / 2]$, then $X^{*}$ is $E S$;

(iii) If $\alpha \in(1 / 2,1)$, then $X^{*}$ is $E S$ if $N<\frac{4 \alpha-1}{2 \alpha-1}$ and $X^{*}$ is $E U$ if $N>\frac{4 \alpha-1}{2 \alpha-1}$.

According to Proposition 3, if the contestants have high productivity from lotteries from zero effort ( $\alpha$ small), then they know that their efforts and opponents' efforts are significant in determining the individual probability of winning. Hence, the aggregate effort is a good focal point, independently of the number of participants. On the contrary, if the contestants have low productivity from lotteries from zero effort ( $\alpha$ large), the aggregate effort is a good focal point for optimal individual decisions only when there is a small number of players. With a large number of participants, the equilibrium is unstable and there can be deviations from the equilibrium (aggregate over- or under-effort). This is the case when we see unexpected results in some presidential elections or referendums.

Proposition 3 is consistent with Hansen (2016)'s argument that presidential elections in the USA have changed significantly since 1993. He highlights three important facts: 
(i) Competition for the position has intensified, with very small margins of victory and a decrease in the number of "swing" states. (ii) The number of voters who consider themselves "strong" partisans, whether Republican or Democratic, has risen. (iii) Regulatory changes, such as same-day registration and early voting, have spread the ballot out. Each of these facts is evidence of an increase in parameter $\alpha$ : marginal changes in a candidate's effort become less effective in changing their probability of winning. From the first fact, the return on effort in states that are no longer key in the presidential election has decreased dramatically. From (ii), there is a higher number of voters who are not likely to change their preferences. Finally, since the opportunity to vote is spread over more days and modalities, so must be the effort to mobilize voters. A drastic reduction in $\alpha$ undermines the stability properties of the game, explaining the unpredictability of the most recent presidential elections in the USA.

\subsection{Public goods provision games}

Cournot and contest games are examples of aggregative games where players are competitors rather than collaborators. The payoff functions are decreasing in the aggregate strategy and may be increasing or decreasing in the individual strategy. A quite different example is the model of contribution for the provision of a public good. In this case, contributions to the constitution of a public good involve a cost, whereas consuming the public good increases the player's payoff. Hence, payoffs are decreasing in the individual strategy but increasing in the aggregate strategy.

Consider a public goods provision game with $N \geq 2$ contributors. The utility function of contributor $i$ is given by the constant elasticity of substitution (CES) utility function $U_{i}(z, G)=\left(\beta_{i} z^{\alpha_{i}}+\left(1-\beta_{i}\right) X^{\alpha_{i}}\right)^{1 / \alpha_{i}}$, where $z \geq 0$ is the expenditure on private goods consumption, $X \geq 0$ is the total amount of the public good (for simplicity, it is equal to players' total monetary contribution) and $\alpha_{i}, \beta_{i} \in(0,1)$ are parameters. If individual $i$ has wealth $m_{i}>0$ and spends $x \geq 0$ units of money to provide public good $X$, then the payoff function is $u_{i}(x, X)=\left(\beta_{i}\left(m_{i}-x\right)^{\alpha_{i}}+\left(1-\beta_{i}\right) X^{\alpha_{i}}\right)^{1 / \alpha_{i}}$. The replacement function of individual $i$ is:

$$
r_{i}(X)= \begin{cases}m_{i}-K_{i} X ; & \text { if } X \leq K_{i}^{-1} m_{i} \\ 0 ; & \text { otherwise }\end{cases}
$$


where $K_{i}=\left(\frac{\beta_{i}}{1-\beta_{i}}\right)^{1 /\left(1-\alpha_{i}\right)}$. Therefore, the greater player $i$ 's perception of the aggregate contribution, the lower the contribution for the public good. As in the previous examples, the next proposition characterizes the results for the case in with homogeneous players.

Proposition 4. In the public goods contribution game played by $N \geq 2$ individuals with identical payoff functions $u(x, X)=\left(\beta(m-x)^{\alpha}+(1-\beta) X^{\alpha}\right)^{1 / \alpha}, \alpha, \beta \in(0,1)$ and initial wealth $m>0$ :

(i) There exists a unique strictly positive $N E X^{*}=\frac{m N}{1+K N}$ where $K=\left(\frac{\beta}{1-\beta}\right)^{1 /(1-\alpha)}$;

(ii) The NE $X^{*}$ is ES if and only if $N<K^{-1}$.

It is interesting to notice that the greater the number of participants, the higher the total contribution to the public good provision. However, the equilibrium becomes unstable as the number of individuals increases and exceeds a certain threshold level. As the slope of the P-T-A is negative, the actual contribution after an optimistic expectation above the Nash total contribution equilibrium is smaller than the equilibrium total contribution. Conversely, the actual contribution for the public good rises after a pessimistic expectation. This under- and over-contribution to a public good (contribution for charity) was documented and analyzed by Bag and Roy (2008) and Bag and Roy (2011) using games with incomplete information played in two-stages.

Another interesting behavior occurs when $N=K^{-1}=((1-\beta) / \beta)^{1 /(1-\alpha)}$. In this case, the slope of the P-T-A function is -1 and a continuum of cycles on an order of 2 arises in the dynamics of expectations represented by equation (2) in a neighborhood of the NE. Therefore, any deviation from the NE will oscillate around it following a cycle of order 2.

\subsection{Bertrand competition games}

In all previous examples, the payoff functions were monotonic on $X$. In this last model presented by Jensen (2016), we explore an example in which an individual's payoffs may be decreasing or increasing functions of the aggregate strategy of the game depending on the level of the individual strategy. 
Consider $N \geq 2$ firms competing à la Bertrand with differentiated products. Let $p_{i}$ be the unit price of good produced by firm $i$. The demand for this good is:

$$
D_{i}\left(p_{i}, p_{-i}\right)=\frac{p_{i}^{\alpha_{i}}}{p_{i} \sum_{j=1}^{N} p_{j}^{\alpha_{j}}}
$$

where $\alpha_{i}<1$ is a preference parameter. A good produced by firm $j$ complements a good produced by firm $i$ if $\alpha_{j}>0$. These goods are substitutes when $\alpha_{j}<0$.

Using the same notation as in the previous examples, let $x_{i}=p_{i}^{\alpha_{i}}$ and assume that firm $i$ has a constant unit $\operatorname{cost} c_{i}$. Then, the payoff function is $u_{i}(x, X)=\frac{x}{X}-c_{i} \frac{x^{\sigma_{i}}}{X}$, where $\sigma_{i}=1-\alpha_{i}^{-1}$. As stated before, depending on the value of $x$, the payoff function can be a decreasing or increasing function of $X$.

The inverse replacement function is

$$
X_{i}(r)=r_{i}^{-1}(r)=\frac{r-c_{i} r^{\sigma_{i}}}{1-c_{i} \sigma r^{\sigma_{i}-1}}
$$

The following result applies to the case in which firms are homogeneous $\left(c_{i}=c\right.$ and $\alpha_{i}=\alpha$ for all $\left.i\right)$ and offer substitute goods ( $\alpha<0$ and consequently $\left.\sigma>1\right)$.

Proposition 5. In the Bertrand competition model with $N \geq 2$ technologically identical firms competing with differentiated products and with payoff functions $u(x, X)=\frac{x}{X}-c \frac{x^{\sigma}}{X}$, where $c>0$ and $\sigma>1$ :

(i) There exists a unique positive $N E X^{*}=N\left(\frac{N-1}{c(\sigma N-1)}\right)^{1 /(\sigma-1)}$.

(ii) The $N E X^{*}$ is ES for all $N \geq 2$.

As in the case of the contest game with a high curvature in the technology for lotteries, the Bertrand model has an ES NE for all $N \geq 2$. Product substitutability in this competition is enough to guarantee the stability of expectations of the equilibrium, and the aggregate price is a good focal point. The robustness of the equilibrium in this oligopolistic competition model is analogous to that of the monopolistic competition, where firms offer differentiated products. In terms of the payoff function, the negative effect of an increase 
in the aggregate price (index) $X$ on revenues $(x / X)$, which results from a decrease in competitors' prices since $x_{j}=p_{j}^{\alpha}$ with $\alpha<0$, is compensated by its positive effect of reducing costs $\left(c x^{\sigma} / X\right)$. The success of eductive learning in models with product differentiation is not surprising, since it was already analyzed in another framework by Guesnerie (1992).

\section{Conclusions}

In this work, we introduce the eductive learning process (expectational dynamics) into aggregative games in order to analyze the convergence of a process to the NE, which is the rational expectation equilibrium of the model. Introducing this process is relevant in these type of games because the aggregate strategy is the natural candidate as an endogenous focal point of the game. The convergence of the process to the NE is interpreted as the robustness of the equilibrium to (small) deviations of expectations of the aggregate strategy from the equilibrium, and consequently, the sustainability of the system in equilibrium. On the other hand, the instability of the equilibrium with respect to the expectational dynamics explains under or over-contributions to the aggregate strategy and may be interpreted as a suggestion to choose a different paradigm to model the problem.

We illustrate the proposed analytical method through four classical models of aggregative games: Cournot oligopolistic competition, the contest game, the public goods provision game, and Bertrand oligopolistic competition with differentiated products. Most models exhibited a standard property: as the number of participants increases, the (Nash) equilibrium of the game becomes unstable. We analyze the cases in which this property is not satisfied and we conclude that either the high curvature of the costs included in the payoff function in the contest game or its non-monotonicity with respect to the aggregate strategy in the Bertrand competition game are responsible for the stability of the equilibrium, even when the number of agents increases.

More than a general result, this work is intended to introduce the eductive learning process to aggregative games and to use the criterion of stability to classify the robustness of the equilibrium and of the model itself. 


\section{Appendix}

\section{Proof of Theorem 1}

The P-T-A map satisfies the first order condition for interior solution:

$$
u_{1}\left(\frac{\rho(X)}{N}, X\right)+u_{2}\left(\frac{\rho(X)}{N}, X\right)=0
$$

Taking the derivative with respect to $X$ and replacing $X$ by $X^{*}$ :

$$
u_{11}\left(x^{*}, X^{*}\right) \frac{\rho^{\prime}\left(X^{*}\right)}{N}+u_{12}\left(x^{*}, X^{*}\right)+u_{21}\left(x^{*}, X^{*}\right) \frac{\rho^{\prime}\left(X^{*}\right)}{N}+u_{22}\left(x^{*}, X^{*}\right)=0
$$

From assumption 1:

$$
\rho^{\prime}\left(X^{*}\right)=N\left(\frac{u_{12}^{*}+u_{22}^{*}}{u_{11}^{*}+u_{21}^{*}}\right)=N \Delta
$$

therefore, there is stability if $\left|\rho^{\prime}\left(X^{*}\right)\right|<1$, which means $|\Delta|<N^{-1}$. Conversely, instability occurs if $\left|\rho^{\prime}\left(X^{*}\right)\right|>1$, which means $|\Delta|>N^{-1}$.

\section{Proof of Proposition 1}

(i) Solving equation $\rho(X)=X$ we find $X^{*}=\left(\frac{A}{c}\left(1-\frac{a}{N}\right)\right)^{1 / a}$, which is strictly positive if and only if $a<N$.

(ii) After straightforward calculation, the derivative of the P-T-A map in the Nash equilibrium $X^{*}$ is $\rho^{\prime}\left(X^{*}\right)=a+1-N$. The necessary and sufficient condition for local monotonic ES of the equilibrium is $0 \leq \rho^{\prime}\left(X^{*}\right)<1$; substitution of $\rho^{\prime}\left(X^{*}\right)$ implies $a<N \leq a+1$.

(iii) The necessary and sufficient condition for local oscillating ES is $-1 \leq \rho^{\prime}\left(X^{*}\right)<0$. We then have $a+1<N \leq a+2$.

(iv) The local instability of $X^{*}$ arises when $\left|\rho^{\prime}\left(X^{*}\right)\right|=N-a-1>1$, therefore when $N>a+2$. If the maximum of $\rho(X)$ is not greater than $(A / c)^{1 / a}$ (the maximum value of $X$ such that $\rho(X) \geq 0$ ), then the dynamics will be chaotic on the interval $I=\left[0,\left((A / c)^{1 / a}\right]\right.$; otherwise, the dynamics will take place in a Cantor subset of $I$ 
(see de Melo and van Strien (1993)). The maximum value of $\rho(X)$ is $\rho(X)^{\max }=$ $N(A / c)^{1 / a}(a+1)^{-1-1 / a}$.

Therefore, the dynamics is chaotic on $I$ if and only if $N>a+2$ and $\rho(X)^{\max } \leq$ $(A / c)^{1 / a}$, which is equivalent to $N \leq(a+1)^{1+1 / a} \equiv v(a)$. The function $v(x)=$ $(x+1)^{1+1 / x}$ is defined for all $x>0$, strictly increasing and $v(x)>x+2$ for all $x>0$. Thus, the dynamics is chaotic on $I$ if and only if $a+2<N \leq v(a)$.

(v) The dynamics is chaotic in a Cantor subset of $I$ if and only if $N>a+2$ and $\rho(X)^{\max }>(A / c)^{1 / a}$, which is equivalent to $N>(a+1)^{1+1 / a}=v(a)>a+2$, therefore, when $N>v(a)$.

\section{Proof of Proposition 2}

The proof is straightforward from setting $a=1$ in the proof of Proposition 1.

\section{Proof of Lemma 1}

(i) The first order condition for the individual problem is $R X^{-1}-\sigma r^{\sigma-1}-R r X^{-2}=0$. Equivalently, we can write $F(r, X) \equiv R X-R r-\sigma r^{\sigma-1} X^{2}=0$. It is not difficult to check that the second-order condition is also satisfied. Our first task is to show the existence and uniqueness of $r=r(X)$ such that $F(r(X), X)=0$. For each $X>0$, we know that $F(0, X)>0$ and $F(+\infty, X)<0$; therefore, there exists $r(X)>0$ such that $F(r(X), X)=0$. For each $X>0$, the derivative $F_{1}(r, X)=-R-\sigma(\sigma-1) r^{\sigma-2} X^{2}<0$; therefore $F(\cdot, X)$ is strictly decreasing in $r$. Hence, there exists a unique $r(X)$ such that $F(r(X), X)=0$. The differentiability of $r(X)$ results from the implicit function theorem applied to the equation $F(r, X) \equiv R X-R r-\sigma r^{\sigma-1} X^{2}=0$.

(ii) Using the implicit function theorem we have:

$$
\frac{d r}{d X}=-\frac{R-2 \sigma r^{\sigma-1} X}{-R-\sigma(\sigma-1) r^{\sigma-2} X^{2}}
$$

The sign of $r^{\prime}(X)$ is equal to the sign of $R-2 \sigma r^{\sigma-1} X$. Using the first-order condition, this last expression has the same sign as $r-(X / 2)$. From (6), in the region $r>X / 2$ 
we have $r^{\prime}(X)>0$, while in $r<X / 2$ it must be that $r^{\prime}(X)<0$. We conclude that the replacement function is an unimodal map. Its maximum is the intersection of the first-order condition equation and $r=X / 2$, which is $X^{m}=2\left(\frac{\alpha R}{4}\right)^{\alpha}$.

From $F(r, X)=0, r(X)<X$, so $\lim _{X \rightarrow 0} r(X)=0$. Also, from the same equation we have:

$$
\sigma r^{\sigma-1}=\frac{R}{X}\left(1-\frac{r}{X}\right)
$$

Since the term in parenthesis is in $(0,1), \lim _{X \rightarrow \infty} r(X)=0$. Finally, using (6), we have that $\lim _{X \rightarrow 0} r^{\prime}(X)=1$.

(iii) Since $\rho(X)=N r(X)$, applying all the results of part (ii) we have the enunciated properties for $\rho(X)$.

\section{Proof of Proposition 3}

Substituting $r(X)=\frac{\rho(X)}{N}$ in the first-order condition given in the proof of Lemma 1 the function $\rho=\rho(X)$ is implicitly defined by:

$$
R X-R \frac{\rho}{N}-\sigma\left(\frac{\rho}{N}\right)^{\sigma-1} X^{2}=R N^{\sigma-1} X-R N^{\sigma-2} \rho-\sigma \rho^{\sigma-1} X^{2}=0
$$

(i) Substituting $\rho=X$ in the last equation, we obtain $X^{*}$ as in the proposition.

(ii) Let us apply Theorem 1 . The value of $\Delta$ in this case is:

$$
\Delta=\frac{2-N}{(\sigma-1) N-(\sigma-2)} \leq 0
$$

To have ES, $|\Delta|<1$, which means $(\sigma-2) N>\sigma-4$. Because $\alpha \in(0,1 / 2]$, we have that $\sigma=\alpha^{-1} \geq 2$; therefore $\sigma-4<\sigma-2 \leq(\sigma-2) N$ and the equilibrium is ES.

(iii) Once again, the condition for ES is $(\sigma-2) N>\sigma-4$ and $\sigma<2$ (because $\alpha \in(1 / 2,1))$. Therefore $N<\frac{\sigma-4}{\sigma-2}=\frac{4 \alpha-1}{2 \alpha-1}$. Conversely, $X^{*}$ is EU if $N>\frac{4 \alpha-1}{2 \alpha-1}$. 


\section{Proof of Proposition 4}

Given the replacement function, the P-T-A map is:

$$
\rho(X)=\left\{\begin{array}{l}
m N-K N X \text { if } X \leq m K^{-1} \\
0 \text { otherwise }
\end{array}\right.
$$

where $K=\left(\frac{\beta}{1-\beta}\right)^{1 /(1-\alpha)}$.

(i) Solving $\rho(X)=X$ we find $X^{*}=\frac{m N}{1+K N}$.

(ii) We could use the Theorem 1, but in this case, where the P-T-A map is linear, it is easier to use $\left|\rho^{\prime}\left(X^{*}\right)\right|<1$ or $K N<1$ which implies $N<K^{-1}$ as the condition for ES.

\section{Proof of Proposition 5}

Let us prove that the P-T-A map $\rho(X)$ is strictly increasing, with $\rho^{\prime}\left(0^{+}\right)=N$ and with an horizontal asymptote in $\rho=N\left(\frac{1}{c \sigma}\right)^{(\sigma-1)^{-1}}$

The first-order condition that defines $r(X)$ is $\left(1-c \sigma r^{\sigma-1}\right) X^{-1}-\left(r-c r^{\sigma}\right) X^{-2}=0$, so we can express explicitly the inverse replacement function as:

$$
X=X(r)=\frac{r\left(1-c r^{\sigma-1}\right)}{1-c \sigma r^{\sigma-1}}
$$

This function has the following properties: $X(0)=0, X^{\prime}(0)=1, X(r)$ is strictly increasing in $\left[0,\left(\frac{1}{c \sigma}\right)^{(\sigma-1)^{-1}}\right)$ and in $\left(\left(\frac{1}{c \sigma}\right)^{(\sigma-1)^{-1}},+\infty\right]$. It is non-negative only in the union of intervals $\left[0,\left(\frac{1}{c \sigma}\right)^{(\sigma-1)^{-1}}\right] \cup\left[\left(\frac{1}{c}\right)^{(\sigma-1)^{-1}},+\infty\right]$. Figure 6 shows the shape of the equation.

For each $X_{0}>0$ there are two possible values for the replacement function (both satisfying the second-order condition of the problem, which can be easily checked). However, using (7) we can calculate:

$$
u\left(r_{1}, X_{0}\right)=1-c \sigma r_{1}^{\sigma-1}>1-c \sigma r_{2}^{\sigma-1}=u\left(r_{2}, X_{0}\right)
$$




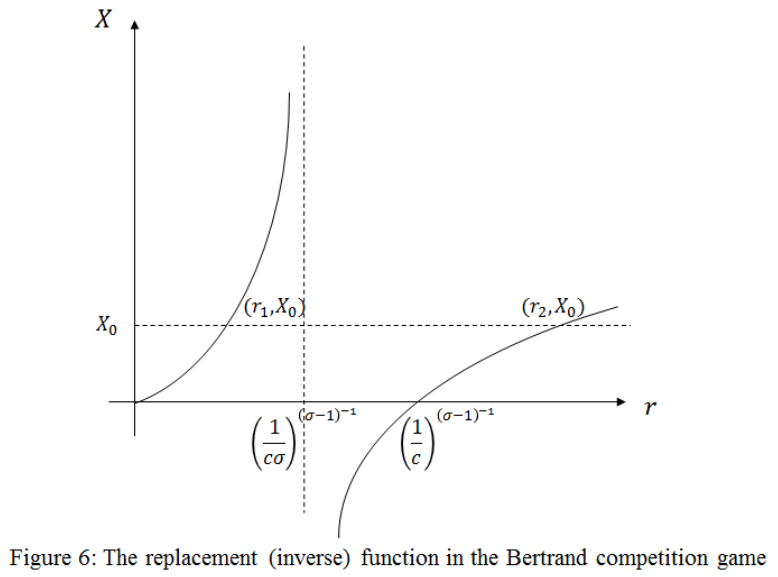

Therefore, the inverse replacement function is defined on the interval $\left[0,\left(\frac{1}{c \sigma}\right)^{(\sigma-1)^{-1}}\right]$. Hence, the P-T-A function inherits the shape of the replacement function, since $\rho(X)=$ $N r(X)$; so $\rho^{\prime}(0)=N$ is a strictly increasing function and has an horizontal asymptote in $\rho=N\left(\frac{1}{c \sigma}\right)^{(\sigma-1)^{-1}}$. We conclude that there exists only one $X^{*}$ satisfying $\rho\left(X^{*}\right)=X^{*}$ which is also ES (this proves part (ii)).

$X^{*}$ can be easily calculated by substituting $r=X^{*} / N$ in equation (7), which proves part (i).

\section{References}

Al-Nowaihi, A. and P. L. Levine (1985). The stability of the Cournot oligopoly model: A reassessment. Journal of Economic Theory 35, 307-321.

Bag, P. K. and S. Roy (2008). Repeated charitable contributions under incomplete information. Economic Journal 118, 6091.

Bag, P. K. and S. Roy (2011). On sequential and simultaneous contributions under incomplete information. International Journal of Game Theory 40, 119145.

Balasko, Y. (1994). The expectational stability of walrasian equilibria. Journal of Mathematical Economics 23, 179-203. 
Chiarella, C. and F. Szidarovszky (2002a). The asymptotic behavior of dynamic rentseeking games. Computers and Mathematics with Applications 43, 169-178.

Chiarella, C. and F. Szidarovszky (2002b). The birth of limit cycles in nonlinear oligopolies with continuously distributed information lags. In M. Dror, P. L'Ecuyer, and F. Szidarovszky (Eds.), Modeling Uncertainty: An Examination of Stochastic Theory, Methods, and Applications, Chapter 12, pp. 249-268. New York, Boston, Dordrecht, London, Moscow: Kluwer Academic Publishers.

Chiarella, C. and F. Szidarovszky (2004). Dynamic oligopolies without full information and with continuously distributed time lags. Journal of Economic Behavior ES Organization 54, 495-511.

Corchón, L. C. (1994). Comparative statics for aggregative games: The strong concavity case. Mathematical Social Sciences 28, 151-165.

Cornes, R. and R. Hartley (2005a). Asymmetric contests with general technologies. Economic Theory 26, 923946.

Cornes, R. and R. Hartley (2005b). The geometry of aggregative games. University of Nottingham Discussion Papers (05/04).

Cornes, R. and R. Hartley (2007a). Aggregative public good games. Public Economic Theory 9(2), 201-219.

Cornes, R. and R. Hartley (2007b). Weak links, good shots and other public good games: Building on bbv. Journal of Public Economics 91(9), 16841707.

Dastidar, K. G. (2000). Is a unique Cournot equilibrium locally stable? Games and Economic Behavior 32, 206-218.

de Melo, W. and S. van Strien (1993). One-Dimensional Dynamics, Volume 25. SpringerVerlag Berlin Heidelberg.

Dindos, M. and C. Mezzetti (2006). Better-reply dynamics and global convergence to nash equilibrium in aggregative games. Games and Economic Behavior 54, 261292. 
Dubey, P., O. Haimanko, and A. Zapechelnyuk (2006). Strategic complements and substitutes, and potential games. Games and Economic Behavior 54, 77-94.

Ellison, M. and J. Pearlman (2011). Saddle-path learning. Journal of Economic Theory 146, $1500-1519$.

Evans, G. (1985). Expectational stability and the multiple equilibria problem in linear rational expectations models. The Quarterly Journal of Economics 100(4), 1217-1233.

Evans, G. W. and R. Guesnerie (1993). Rationalizability, strong rationality and expectational stability. Games and Economic Behavior 5, 632-646.

Evans, G. W. and R. Guesnerie (2005). Coordination on saddle-path solutions: the eductive viewpointlinear multivariate models. Journal of Economic Theory 124, 202229.

Evans, G. W. and S. Honkapohja (2003). Expectational stability of stationary sunspot equilibria in a forward-looking linear model. Journal of Economic Dynamics and Control 28, $171-181$.

Frank-Jr., C. R. and R. E. Quandt (1963). On the existence of Cournot equilibrium. International Economic Review 4(1), 1254-1278.

Gaballo, G. (2013). Eductive learning and the rationalizability of oligopoly games. Economic Letters 120, 401-404.

Guesnerie, R. (1992). An exploration of the eductive justifications of the rationalexpectations hypothesis. American Economic Review 82(5), 12541278.

Hahn, F. H. (1962). The stability of the Cournot oligopoly solution. The Review of Economic Studies 29(4), 329-331.

Hansen, J. M. (2016). Mobilization, participation, and political change. Party Politics 22(2), 149-157.

Jensen, M. K. (2010). Aggregative games and best-reply potentials. Economic Theory 43, 45-66.

Jensen, M. K. (2016). Aggregative games. In E. L. Corchn and M. A. Marini (Eds.), Handbook of Game Theory and Industrial Organization. Edward Alger. To appear. 
McManus (1964, November). Equilibrium, numbers and size in Cournot oligopoly. Bulletin of Economic Research 16(2), 68-75.

Novshek, W. (1985). On the existence of Cournot equilibrium. Review of Economic Studies 52(1), 112-117.

Okuguchi, K. (1976). Expectations and Stability in Oligopoly Models, Volume 138. Lecture Notes in Economics and Mathematical Systems. Springer-Verlag Berlin Heidelberg.

Okuguchi, K. (1993). Unified approach to Cournot models: oligopoly, taxation and aggregate provision of a pure public good. European Journal of Political Economy 9, 233-245.

Okuguchi, K. and F. Szidarovszky (1999). The Theory of Oligopoly with Multi-Product Firms (2nd Edition). Springer-Verlag Berlin Heidelberg.

Okuguchi, K. and T. Yamazaki (2008). Global stability of unique nash equilibrium in Cournot oligopoly and rent-seeking game. Journal of Economic Dynamics and Control 32, 1204-1211.

Possajennikov, A. (2003). Evolutionary foundations of aggregate-taking behavior. Economic Theory 21, 921-928.

Possajennikov, A. (2015). Conjectural variations in aggregative games: An evolutionary perspective. Mathematical Social Sciences 77, 55-61.

Roberts, J. and H. Sonnenschein (1976). On the existence of Cournot equilibrium without concave profit functions. Journal of Economic Theory 13, 112-117.

Selten, R. (1970). Preispolitik der Mehrproduktenunternehmung in der statischen Theorie, Volume 16. Berlin: Springer Berlin Heidelberg.

Szidarovsky, F. and K. Okugushi (1997). On the existence and uniqueness of pure nash equilibrium in rentseeking games. Games and Economic Behavior 18, 135-140.

Szidarovsky, F. and S. Yakowitz (1977, October). A new proof of the existence and uniqueness of the Cournot equilibrium. International Economic Review 18(3), 787789.

Tullock, G. (1980). Toward a theory of the rent-seeking society, Chapter Efficient rentseeking, pp. 97-112. College Station: Texas A\&M University Press. 
Editor, UWA Economics Discussion Papers:

Sam Hak Kan Tang

University of Western Australia

35 Sterling Hwy

Crawley WA 6009

Australia

Email: ecoadmin@biz.uwa.edu.au

The Economics Discussion Papers are available at:

1980 - 2002: http://ecompapers.biz.uwa.edu.au/paper/PDF\%20of\%20Discussion\%20Papers/

Since 2001: $\quad$ http://ideas.repec.org/s/uwa/wpaper1.html

Since 2004: $\quad$ http://www.business.uwa.edu.au/school/disciplines/economics

\begin{tabular}{|c|c|c|}
\hline \multicolumn{3}{|c|}{ ECONOMICS DISCUSSION PAPERS - 2016} \\
\hline $\begin{array}{l}\text { DP } \\
\text { NUMBER }\end{array}$ & AUTHORS & TITLE \\
\hline 16.01 & $\mathrm{Xu}, \mathrm{R} ., \mathrm{Wu}, \mathrm{Y}$. and Luan, J. & $\begin{array}{l}\text { ANALYSIS OF FARMERS' WILLINGNESS TO ADOPT } \\
\text { GENETICALLY MODIFIED INSECT-RESISTANT RICE IN } \\
\text { CHINA }\end{array}$ \\
\hline 16.02 & $\begin{array}{l}\text { Lia, Y., Fan, J., Zhao, D., Wu, Y. and } \\
\text { Li, J. }\end{array}$ & $\begin{array}{l}\text { TIERED GASOLINE PRICING: A PERSONAL CARBON } \\
\text { TRADING PERSPECTIVE }\end{array}$ \\
\hline 16.03 & Clements, K.W., Lan, Y. and Si, J. & UNCERTAINTY IN CURRENCY MISPRICING \\
\hline 16.04 & Parsons, C. and Vézina, P.L. & $\begin{array}{l}\text { MIGRANT NETWORKS AND TRADE:THE VIETNAMESE } \\
\text { BOAT PEOPLE AS A NATURAL EXPERIMENT }\end{array}$ \\
\hline 16.05 & Chang, S., Connelly, R. and Ma, P. & $\begin{array}{l}\text { WHAT WILL YOU DO IF I SAY ‘I DO’?: THE EFFECT OF } \\
\text { THE SEX RATIO ON TIME USE WITHIN TAIWANESE } \\
\text { MARRIED COUPLES }\end{array}$ \\
\hline 16.06 & $\mathrm{Yu}, \mathrm{F}$. and $\mathrm{Wu}, \mathrm{Y}$. & $\begin{array}{l}\text { BIASES IN PATENT EXAMINATION AND FIRMS' } \\
\text { RESPONSES: EVIDENCE FROM THE } \\
\text { PHARMACEUTICAL INDUSTRY }\end{array}$ \\
\hline 16.07 & $\begin{array}{l}\text { Fan, J., Li, J., Wu, Y., Wang, S. and } \\
\text { Zhao, D. }\end{array}$ & $\begin{array}{l}\text { THE EFFECTS OF ALLOWANCE PRICE ON ENERGY } \\
\text { DEMAND UNDER A PERSONAL CARBON TRADING } \\
\text { SCHEME }\end{array}$ \\
\hline 16.08 & Golley, J., Tyers, R. and Zhou, Y. & $\begin{array}{l}\text { CONTRACTIONS IN CHINESE FERTILITY AND } \\
\text { SAVINGS: LONG RUN DOMESTIC AND GLOBAL } \\
\text { IMPLICATIONS }\end{array}$ \\
\hline 16.09 & McGrath, G. and Neill, K. & $\begin{array}{l}\text { FOREIGN AND DOMESTIC OWNERSHIP IN WESTERN } \\
\text { AUSTRALIA'S GAS MARKET }\end{array}$ \\
\hline 16.10 & Clements, K.W. and Si, J. & SIMPLIFYING THE BIG MAC INDEX \\
\hline 16.11 & Priyati, R.Y. and Tyers, R. & $\begin{array}{l}\text { PRICE RELATIONSHIPS IN VEGETABLE OIL AND } \\
\text { ENERGY MARKETS }\end{array}$ \\
\hline 16.12 & Wu, J., Wu, Y. and Wang, B. & $\begin{array}{l}\text { THE GREENNESS OF CHINESE CITIES: CARBON } \\
\text { DIOXIDE EMISSION AND ITS DETERMINANTS }\end{array}$ \\
\hline 16.13 & $\begin{array}{l}\text { Arslan, C., Dumont, J.C., Kone, Z., } \\
\text { Özden, Ç., Parsons, C. and } \\
\text { Xenogiani, T. }\end{array}$ & $\begin{array}{l}\text { INTERNATIONAL MIGRATION TO THE OECD IN THE } \\
\text { TWENTY-FIRST CENTURY }\end{array}$ \\
\hline 16.14 & Tomioka, K. and Tyers, R. & $\begin{array}{l}\text { HAS FOREIGN GROWTH CONTRIBUTED TO } \\
\text { STAGNATION AND INEQUALITY IN JAPAN? }\end{array}$ \\
\hline 16.15 & Donovan, J. and Hartley, P. & $\begin{array}{l}\text { RIDING THE IRON ORE CYCLE: ACTIONS OF } \\
\text { AUSTRALIA'S MAJOR PRODUCERS }\end{array}$ \\
\hline 16.16 & Czaika, M. and Parsons, C. & $\begin{array}{l}\text { HIGH-SKILLED MIGRATION IN TIMES OF GLOBAL } \\
\text { ECONOMIC CRISIS }\end{array}$ \\
\hline
\end{tabular}




\begin{tabular}{|l|l|l|}
\hline 16.17 & Lefroy, T., Key, J. and Kingwell, R. & $\begin{array}{l}\text { A LONGITUDINAL EXAMINATION OF BROADACRE } \\
\text { FARM SIZE AND PERFORMANCE IN WESTERN } \\
\text { AUSTRALIA }\end{array}$ \\
\hline 16.18 & Arthmar, R. and McLure, M. & $\begin{array}{l}\text { SRAFFA, MYRDAL AND THE 1961 SÖDERSTRÖM GOLD } \\
\text { MEDAL }\end{array}$ \\
\hline 19.19 & Azwar, P. and Tyers, R. & $\begin{array}{l}\text { POST-GFC EXTERNAL SHOCKS AND INDONESIAN } \\
\text { ECONOMIC PERFORMANCE }\end{array}$ \\
\hline 19.20 & Chen, A. and Groenewold, N. & $\begin{array}{l}\text { OUTPUT SHOCKS IN CHINA: DO THE DISTRIBUTIONAL } \\
\text { EFFECTS DEPEND ON THE REGIONAL SOURCE? }\end{array}$ \\
\hline 19.21 & Wu, Y., Zhu, X. and Groenewold, N. & $\begin{array}{l}\text { THE DETERMINANTS AND EFFECTIVENESS OF } \\
\text { INDUSTRIAL POLICY IN CHINA: A STUDY BASED ON } \\
\text { FIVE-YEAR PLANS }\end{array}$ \\
\hline 16.22 & Liu, H. & $\begin{array}{l}\text { THE INCOME AND PRICE SENSITIVITY OF DIETS } \\
\text { GLOBALLY }\end{array}$ \\
\hline 16.23 & Asano, A., Neill, K. and Yamazaki, S. & $\begin{array}{l}\text { DECOMPOSING FISHING EFFORT: MODELLING THE } \\
\text { SOURCES OF INEFFICIENCY IN A LIMITED-ENTRY } \\
\text { FISHERY }\end{array}$ \\
\hline 16.24 & Golley, J., Tyers, R. and Zhou, Y. & $\begin{array}{l}\text { FERTILITY AND SAVINGS CONTRACTIONS IN CHINA: } \\
\text { LONG-RUN GLOBAL IMPLICATIONS }\end{array}$ \\
\hline 16.25 & Taylor, G., Tyers, R. & $\begin{array}{l}\text { Secular Stagnation: Determinants and Consequences for } \\
\text { Australia }\end{array}$ \\
\hline
\end{tabular}

\begin{tabular}{|l|l|l|}
\hline \multicolumn{2}{|c|}{ ECONOMICS DISCUSSION PAPERS - 2017 } \\
\hline $\begin{array}{c}|c| \\
\text { DP } \\
\text { NUMBER }\end{array}$ & \multicolumn{1}{|c|}{ AUTHORS } & \multicolumn{1}{c|}{ TITLE } \\
\hline 17.01 & Tyers, R. and Zhou, Y. & $\begin{array}{l}\text { AUTOMATION AND INEQUALITY WITH TAXES AND } \\
\text { TRANSFERS }\end{array}$ \\
\hline 17.02 & Ye, L. and Robertson, P. & $\begin{array}{l}\text { HITTING THE GREAT WALL: RURAL-URBAN } \\
\text { MIGRATION AND CHINA'S GROWTH SLOWDOWN }\end{array}$ \\
\hline 17.03 & Ye, L. and Robertson, P. & $\begin{array}{l}\text { MIGRATION AND GROWTH IN CHINA: A SCEPTICAL } \\
\text { ASSESSMENT OF THE EVIDENCE }\end{array}$ \\
\hline 17.04 & Clements, K. Si, J. and Vo, L. & $\begin{array}{l}\text { FOOD AND AGRICULTURAL PRICES ACROSS } \\
\text { COUNTRIES AND THE LAW OF ONE PRICE }\end{array}$ \\
\hline 17.05 & $\begin{array}{l}\text { Chen, M., Clements, K., Gao, G. and } \\
\text { Si, J. }\end{array}$ & $\begin{array}{l}\text { THREE FACTS ABOUT WORLD METAL PRICES } \\
\text { Cornes, R., Fiorini, L. and }\end{array}$ \\
\hline 17.06 & Maldonado, W. & $\begin{array}{l}\text { EXPECTATIONAL STABILITY IN AGGREGATIVE } \\
\text { GAMES }\end{array}$ \\
\hline 17.07 & $\begin{array}{l}\text { THE COST OF DISPLACING FOSSIL FUELS: SOME } \\
\text { EVIDENCE FROM TEXAS }\end{array}$ \\
\hline 17.08 & Shehabi, M. R. & $\begin{array}{l}\text { GSSESSING KUWAITI ENERGY PRICINING REFORMS } \\
\text { INTERACTION OR UNILATERAL GAINS? }\end{array}$ \\
\hline 17.09 & Perdana, S. and Tyers, R. & \\
\hline
\end{tabular}

